\title{
Anti-myeloperoxidase antibodies in patients with rheumatoid arthritis: prevalence, clinical correlates, and IgG subclass
}

\author{
G Cambridge, $M$ Williams, B Leaker, M Corbett, C R Smith
}

\begin{abstract}
Objectives-To determine the prevalence and clinical associations of autoantibodies to myeloperoxidase (MPO) in an unselected series of well-characterised outpatients with rheumatoid arthritis (RA) and to compare the distribution of IgG subclasses of anti-MPO antibodies in these patients with that in patients with systemic vasculitis.

Patients and methods-A study was made of 97 patients with RA, who have been seen regularly in this department for up to 20 years, and 29 patients with anti-neutrophil cytoplasmic antibody (ANCA) positive systemic vasculitis. Anti-MPO antibodies were detected using a direct-binding enzyme-linked immunosorbent assay (ELISA) with MPO from human granulocytes as antigen. The IgG subclass of anti-MPO antibodies was determined by ELISA using isotype specific monoclonal antibodies.
\end{abstract}

Results-Anti-MPO antibodies were detected in $12 \%$ of patients with RA. Six sera contained IgG anti-MPO antibodies only, 1 IgM only and 5 antibodies of both classes. In the patients with $R A$ the predominant subclasses were IgG1 and IgG3: only 2 sera contained detectable IgG4 antibodies. This was in contrast to patients with vasculitis, in whom most sera contained IgG1, IgG3 and IgG4 antiMPO antibodies. Anti-MPO antibodies in sera from both patient groups bound only to the native protein. None of the patients studied with RA had evidence of vasculitis affecting the nerves or kidney: three patients ( 1 positive for anti-MPO antibodies and 2 negative) had cutaneous vasculitis. In the patients with $R A$, positivity for anti-MPO antibodies was associated with nodules and number of active joints. Three patients with anti-MPO antibodies, and none without, had pulmonary fibrosis.

Conclusions-Twelve per cent of a group of unselected outpatients with RA, but without evidence of major systemic vasculitis, had anti-MPO antibodies in their serum. Positivity for anti-MPO antibodies was more common in patients with nodular disease and lung involvement but not in patients with cutaneous vasculitis. IgG4 sub-class antiMPO antibodies were present in $90 \%$ of sera from patients with ANCA-positive vasculitis and only $2 / 11(18 \%)$ of anti-MPO antibody containing sera from patients with RA.

(Ann Rheum Dis 1994; 53: 24-29)

Anti-neutrophil cytoplasmic antibodies giving a cytoplasmic (c-ANCA) or perinuclear (p-ANCA) staining pattern on ethanol-fixed human neutrophils and reacting with lysosomal enzymes have been detected in a high proportion of sera from patients with systemic vasculitis. ${ }^{1}$ Approximately $80 \%$ of p-ANCA positive sera contain antibodies directed against the native form of myeloperoxidase (MPO). ${ }^{2}{ }^{3}$ Specificity for other neutrophil granule enzymes such as lactoferrin and elastase has been described in a minority of p-ANCA staining sera. ${ }^{4}$ Autoantibodies to neutrophils have also been found in sera from patients with other autoimmune conditions, such as systemic lupus erythematosus (SLE), rheumatoid arthritis (RA) and inflammatory bowel disease. $^{56}$

Vasculitis is a characteristic pathological feature of the extra-articular manifestations of RA although systemic and renal vasculitis are rare. Because of the known clinical association of vasculitis with RA, ANCA have been sought in sera from these patients. However, their prevalence and clinical significance remain unclear with conflicting results reported. ${ }^{5-10}$ Many of these differences may be explained by the different methodologies used to characterise these autoantibodies, the small patient numbers and in the selection of patients.

In the largest study of ANCA in RA, ${ }^{5}$ it was found that p-ANCA were present in only $2 \cdot 8 \%$ of 214 patients with RA and c-ANCA in none. Neither Cohen Tervaert et al ${ }^{11}$ nor Nassberger et $a l^{9}$ found antibodies to MPO in sera from a total of 71 patients with RA including 16 patients with severe vasculitis. In contrast, Lassoued $e t a l^{8}$ found 13 of 75 RA sera $(17 \%)$ to be positive for p-ANCA. Of the 13 ANCA positive patients, 6 had vasculitis (of whom 5 had anti-MPO antibodies). This suggestion of an association between anti-MPO antibodies and vasculitis in patients with RA was not supported by the findings of Coremans et al. In a series of 99 patients they found anti-MPO antibodies in sera from $12 \%(6 / 50)$ of patients 
with uncomplicated RA compared with $22 \%$ (11/49) of RA patients with cutaneous or neural vasculitis (this trend did not achieve statistical significance).

There are important differences in the biological activity of immunoglobulin subclasses in terms of their ability to bind and activate complement and in their affinity for Fc receptors. ${ }^{12}$ The sub-class of autoantibodies present in sera from patients with autoimmune disease has been shown to be a contributory factor in pathogenicity. For example, in SLE anti-double stranded DNA (dsDNA) antibodies of the IgG1 and IgG3 subclasses are associated with immunoglobulin deposits in the kidney ${ }^{13}$ whilst circulating IgG1 and IgG2 anti-dsDNA predominate in patients with skin involvement and arthralgia. ${ }^{14}$ Several studies have demonstrated that anti-MPO antibodies in sera from patients with vasculitis contain an increased proportion of the IgG4 subclass. ${ }^{15} 16$

Our study was designed to determine the prevalence, sub-class and possible clinical associations of anti-MPO antibodies in an unselected, well characterised group of patients with rheumatoid arthritis. The class and subclass distribution of anti-MPO antibodies in patients with RA were then compared with those of patients with ANCA positive vasculitis.

\section{Patients and methods}

Patients with rheumatoid arthritis

Ninety seven patients from the Middlesex Hospital RA Prospective Study (RAPS) ${ }^{17} 18$ were studied. All presented within a year of onset of polyarthritis and have been followed up. Patients were classified at entry to the study and at each visit according to the American Rheumatism Association (1958) criteria for RA. ${ }^{19}$ Patients who developed evidence for a diagnosis other than RA (such as psoriatic arthritis) were not included in this study. Seventy seven per cent of patients were classified as having classic or definite RA at the time of this study. Seventeen patients had 'probable' RA, with five having an erosive arthritis; four patients had 'possible' RA. There were 28 men and 69 women, with a mean age of 60 years (28-87 years) and mean disease duration of 13.5 years $(2 \cdot 2-28$ years). A total of $41 \%$ of the patients were currently taking only non-steroidal anti-inflammatory drugs and no disease-modifying drugs (DMARDs), $40 \%$ were taking one DMARD, and $18 \%$ were taking two or more. Thirty patients took sulphasalazine, 14 azathioprine, 12 penicillamine, 7 gold, and 5 each methotrexate and prednisolone.

Three patients had evidence of cutaneous vasculitis at the time of ANCA measurement: two patients had nailfold infarcts, one with digital gangrene, and one patient had vasculitic leg ulcers. Three patients had lung disease: one had rheumatoid nodules, bronchiectasis and interstitial fibrosis; one interstitial fibrosis and bronchiectasis; one interstitial fibrosis alone. Diagnoses were based on clinical findings, lung function tests, radiographs and computed tomographic scans in all patients and lung biopsy in two. In all cases the lung disease was felt to be associated with the RA.

Disease activity in the patients with rheumatoid arthritis was assessed by comparing tender joint count, ESR, haemoglobin, and a global clinical impression of disease activity (disease activity index, DAI) which was graded $0-2$ where 0 represents inactive disease with symptoms, if any, due to degenerative or mechanical factors and 2 represents highly active disease.

\section{Patients with vasculitis}

Twenty nine patients with rapidly progressive renal failure associated with systemic vasculitis were studied. All patients had a renal biopsy which in each case showed pauci-immune focal and segmental glomerulonephritis compatible with a diagnosis of systemic vasculitis. At diagnosis, sera from all patients gave a p-ANCA staining pattern on ethanol-fixed neutrophils.

\section{Normal subjects}

Sera from 50 consecutive normal healthy blood donors, obtained from the Blood Transfusion Unit, were studied as normal controls.

\section{Methods}

Detection of IgM and IgG antibodies to MPO MPO was purified from a primary granule extract of human neutrophils. ${ }^{2021}$ The class of anti-MPO antibodies present in sera was measured using a modification of an ELISA previously established in this laboratory. ${ }^{6}$ Briefly, purified MPO was coated on to ELISA plates at a concentration of $1 \mathrm{ug} / \mathrm{ml}$ in sodium bicarbonate buffer $(0.1 \mathrm{M}, \mathrm{pH} \mathrm{9.6)}$ for two hours at room temperature. Uncoated wells were also included to control for background binding of sera. All subsequent incubations were for one hour at $37^{\circ} \mathrm{C}$. Sera were diluted $1 / 100$ in PBS containing $0.1 \%$ Tween and $2 \%$ bovine serum albumin (PBT) for use. Binding of antibodies to MPO was detected using alkaline phosphatase conjugated goat antihuman IgM or IgG (Sigma Chemical) diluted 1/5000 in PBT with p-nitrophenol phosphate ( $1 \mathrm{mg} / \mathrm{ml}$ in sodium bicarbonate buffer). Following subtraction of background optical density readings, the averages of duplicate wells were calculated. Results were expressed as a percentage of the positive controls for IgG and IgM anti-MPO antibodies. Readings greater than the mean percentage binding $+3 S D$ of 50 normal controls were regarded as positive.

\section{Detection of anti-MPO antibody subclasses}

Aklaline phosphatase conjugated mouse monoclonal antibodies specific for human IgG subclasses were used to measure the isotype of IgG anti-MPO antibodies in 32 sera from patients with IgG anti-MPO antibodies (11 RA and 21 vasculitis) using a modification of a technique previously established in our laboratory. ${ }^{22}$ The basic method and conditions 
were the same as for the detection of class specific anti-MPO antibodies. Sub-class specific alkaline phosphatase conjugated mouse monoclonal antibodies to IgG1-4 (The Binding Site, UK) were used at 1/400 (IgG1), $1 / 40$ (IgG2), $1 / 1000$ (IgG3) and $1 / 1280$ (IgG4). Optical density values greater than mean +3 SD of 20 normal control sera were taken as positive.

\section{Western blotting}

Sera from 20 patients with vasculitis and $10 \mathrm{RA}$ were tested for reactivity with the reduced form of MPO with a standard Western blotting technique. ${ }^{23}$ Briefly, $10 \mu \mathrm{g}$ of purified MPO per lane was run under reducing conditions on $12.5 \%$ SDS-PAGE, transblotted to nitrocellulose sheets and probed with patient sera diluted $1 / 50$ in PBT supplemented with $10 \%$ goat serum and $1 \%$ gelatin. Alkaline phosphatase-conjugated rabbit anti-human immunoglobulins (Southern Biotechnology) and phosphatase naphthol substrate were used as the detection system. A rabbit anti-MPO antibody (Sigma) was used as a positive control and developed with appropriate reagents.

\section{Statistical methods}

Chi-squared analysis was used to compare the presence or absence of anti-MPO antibodies in patients with particular clinical features. Student's $t$ test was used for comparing joint scores, ESR and DAI in patients with RA, with and without anti-MPO antibodies.

\section{Results}

Prevalence and class of anti-MPO autoantibodies Anti-MPO antibodies were detected in sera from 12 patients with rheumatoid arthritis $(12 \%)$, no normal controls and 24 of $29(83 \%)$ patients with ANCA positive vasculitis (table 1). Mean levels of IgM and IgG anti-MPO antibodies were significantly elevated in patients with systemic vasculitis. Although mean levels in RA sera were low compared with those from patients with vasculitis, IgG anti-MPO antibodies were significantly higher than normal controls $(p<0.01$; table 1$)$. Most

Table 1 Prevalence, class and level of anti-MPO antibodies in sera from patients with $R A$ and vasculitis and normal controls

\begin{tabular}{|c|c|c|c|c|c|c|c|}
\hline \multirow{2}{*}{$\begin{array}{l}\text { Patient } \\
\text { group }\end{array}$} & \multirow{2}{*}{$\begin{array}{l}\text { Sample } \\
\text { size }\end{array}$} & \multirow{2}{*}{$\begin{array}{l}\text { Number } \\
\text { positive }\end{array}$} & \multicolumn{3}{|c|}{ Class of anti-MPO antibodies } & \multicolumn{2}{|c|}{ Mean and $S D \%$ binding to $M P O$} \\
\hline & & & IgM only & IgG only & $\operatorname{Ig} M+\operatorname{Ig} G$ & $\operatorname{Ig} M$ & $\operatorname{Ig} G$ \\
\hline RA & 97 & 12 & 1 & 6 & 5 & $13 \cdot 1(15 \cdot 7)$ & $11.5(7 \cdot 6)^{\star}$ \\
\hline Vasculitis & 29 & 24 & 3 & 0 & 21 & $56 \cdot 4(60 \cdot 1)^{\star \star}$ & $74 \cdot 8(73 \cdot 7)^{\star \star}$ \\
\hline Controls & 50 & 0 & 0 & 0 & 0 & $10 \cdot 2(1 \cdot 1)$ & $8.5(1.8)$ \\
\hline
\end{tabular}

* $\mathrm{p}<0.01$.

${ }^{\star *} \mathrm{p}<0.001$

Table 2 Number of sera from patients with $R A$ and vasculitis containing significant levels of each IgG subclass specific for binding to MPO

\begin{tabular}{|c|c|c|c|c|c|}
\hline $\begin{array}{l}\text { Patient } \\
\text { group }\end{array}$ & $\begin{array}{l}\text { Number of } \\
\text { samples }\end{array}$ & $I g G 1$ & $I g G 2$ & $I g G 3$ & $\operatorname{IgG4}$ \\
\hline $\begin{array}{l}\text { Rheumatoid arthritis } \\
\text { Vasculitis }\end{array}$ & $\begin{array}{l}11 \\
21\end{array}$ & $\begin{array}{c}7(64 \%)^{\star} \\
16(76 \%)\end{array}$ & $\begin{array}{l}3(9 \%) \\
3(14 \%)\end{array}$ & $\begin{array}{r}6(55 \%) \\
17(81 \%)\end{array}$ & $\begin{array}{r}2(18 \%) \\
19(90 \%)\end{array}$ \\
\hline
\end{tabular}

$\star$ Percentages are given in brackets.
$(88 \%)$ of the sera from patients with systemic vasculitis had anti-MPO antibodies of both IgG and IgM class, compared with $42 \%$ of sera containing anti-MPO antibodies from patients with RA.

\section{Subclass of anti-MPO antibodies}

Sera from 11 patients with RA and 21 with systemic vasculitis positive for IgG anti-MPO antibodies were analysed for antigen-specific IgG subclasses (table 2). Ninety per cent of IgG anti-MPO antibody positive sera from patients with systemic vasculitis contained IgG4 antibodies to MPO. IgG3 anti-MPO antibodies were also predominant in this group of patients. In contrast, anti-MPO antibodies in RA sera were predominently of the IgG1 and IgG3 subclass, with only $2 / 11(18 \%)$ of sera containing IgG4 anti-MPO antibodies. Of the two patients with RA who had circulating IgG4 anti-MPO antibodies; one was a patient with cutaneous vasculitis who had sera positive for anti-MPO antibodies for 15 years; the other had anti-MPO antibodies for at least two years.

\section{Western blotting}

Antibodies to MPO in both RA and vasculitis were shown to bind only to the native form of the enzyme in ELISA. They did not recognise the reduced form of the enzyme on Western blots (data not shown). This suggests that antiMPO antibodies in RA and vasculitis sera recognise only native protein.

Clinical associations of anti-MPO antibodies in $R A$

The clinical features of patients with RA whose sera contained anti-MPO antibodies were compared with those of patients without these antibodies (table 3). Anti-MPO antibody positivity in patients with rheumatoid arthritis was associated with the presence of nodules $(p<0.05)$, lung involvement $(p<0.001)$ and an increased number of active joints $(p<0.05)$. All three patients with RA associated lung disease had anti-MPO antibodies in their serum. The presence of anti-MPO antibodies was not associated with seropositivity for rheumatoid factor, erosive disease, or the presence of antinuclear antibodies. None of the patients in this study had evidence of a systemic vasculitis and there was no association between the presence of anti-MPO antibodies and cutaneous vasculitis. Two patients (both anti-MPO antibody negative), had renal disease not associated with vasculitis-one gold-induced proteinuria and one mesangiocapillary glomerulonephritis.

Clinical features of the 12 patients with $R A$ and anti-MPO antibodies

Table 4 shows the clinical features of individual patients with RA who were seropositive for anti-MPO antibodies.

Three patients had lung disease compatible with RA-associated lung disease and for which no other cause was found. Patient 3 had mild fibrosing alveolitis with basal crackles, and typical radiographic and lung function 
Table 3 Clinical features of patients with $R A$ with sera positive and negative for antiMPO antibodies

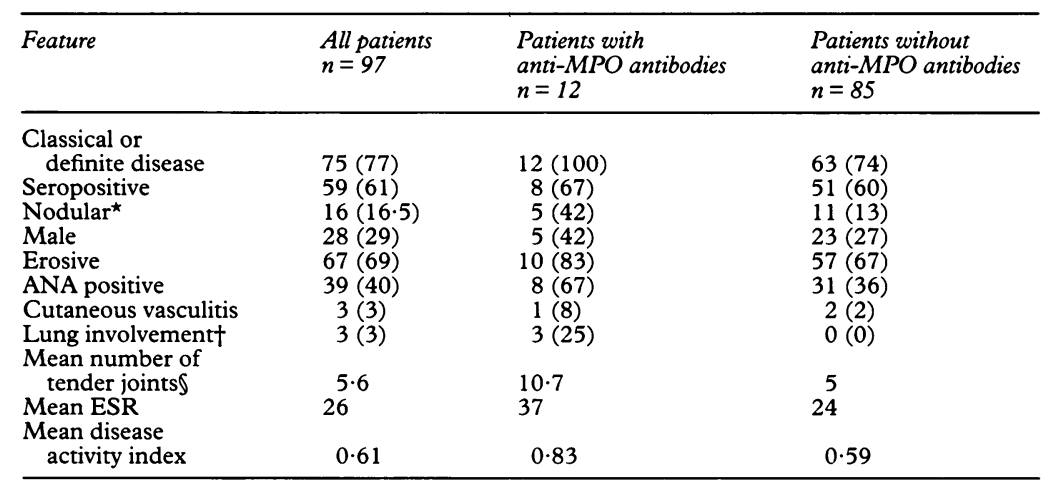

Figures in parentheses are percentages.

$\mathrm{sp}<0.05 t$ test.

${ }^{\star} \mathrm{p}<0.05$ Chi squared test.

$\mathrm{tp}<0.001$.

Table 4 Clinical features of the 12 patients with $R A$ whose sera contained anti-MPO antibodies

\begin{tabular}{|c|c|c|c|c|c|c|c|}
\hline $\begin{array}{l}\text { Patient } \\
\text { number }\end{array}$ & $\begin{array}{l}\text { Cutaneous } \\
\text { vasculitis }\end{array}$ & Nodules & $\begin{array}{l}\text { Lung } \\
\text { involvement }\end{array}$ & $T P O^{\star}$ & $A N A \dagger$ & D-pen $\ddagger$ & $\begin{array}{l}\text { Disease } \\
\text { duration }\end{array}$ \\
\hline 1 & + & + & - & - & $1: 5120$ & + & $27 \cdot 4$ \\
\hline 2 & - & + & - & - & - & - & $21 \cdot 0$ \\
\hline 3 & - & + & + & - & $1: 80$ & + & $19 \cdot 0$ \\
\hline 4 & - & - & - & _- & $1: 160$ & - & 12.8 \\
\hline 5 & - & + & - & + & - & + & 10.0 \\
\hline 6 & - & - & - & + & - & - & 9.5 \\
\hline 7 & - & - & + & - & - & - & $10 \cdot 2$ \\
\hline 8 & - & + & - & - & $1: 320$ & - & 16.0 \\
\hline 9 & - & - & + & - & $1: 80$ & + & $5 \cdot 8$ \\
\hline 10 & - & - & - & - & $1: 80$ & - & $4 \cdot 2$ \\
\hline 11 & - & - & - & + & $1: 640$ & - & $4 \cdot 8$ \\
\hline 12 & - & - & - & - & $1: 320$ & - & 2.2 \\
\hline
\end{tabular}

^TPO: anti-thyroperoxidase (thyroid microsomal) antibodies in titre $>1: 40$.

†ANA: antinuclear antibody.

D-pen: current treatment with D-penicillamine.

DD-pen: current treatment
Disease duration is in years. briskly after penicillamine was started, but IgG anti-MPO antibodies although detectable, remained at low titre.

Patient 2 first had detectable anti-MPO antibodies in her serum at the time she had a chronic staphylococcal infection of a total knee replacement. There was no evidence of vasculitis.

Three patients $(5,6,11)$ had only IgG antiMPO antibodies and a significant titre of antithyroid microsomal antibodies. None of these patients had extra-articular rheumatoid disease: one had symptomatic thyroid disease and had had a thyroidectomy.

Patients 4, 8 and 10 all had long-standing (>10 years) seropositive disease with no extraarticular features. Patient 12 had a three year history of RA with no extra-articular disease.

\section{Discussion}

In this study anti-MPO antibodies were found in sera from approximately $12 \%$ of a group of unselected outpatients with rheumatoid arthritis with varying levels of disease activity. This figure is similar to that reported in several other studies. ${ }^{78}$ We could not confirm an association between the presence of cutaneous vasculitis and anti-MPO antibodies. None of the patients we studied, however, had systemic vasculitis. We confirmed that $83 \%$ of p-ANCA containing sera from patients with systemic vasculitis had specificity for MPO.

Many of the differences between the studies of ANCA in RA may be explained by the different methods used to define antigen specificity. For example, the interpretation of a p-ANCA staining pattern may be complicated by the presence of anti-nuclear antibodies in the same serum, since antibodies of these specificities can cause similar or overlapping staining patterns. Cross reactivity with antithyroid microsomal antibodies, specific for thyroperoxidase (TPO), may result in a positive test for anti-MPO antibodies in ELISA. In a small study in this laboratory (data not shown) it was found that $2 / 10$ sera from patients with anti-TPO antibodies confirmed by specific ELISA (Cambridge Life Sciences) reacted with MPO in ELISA and gave a perinuclear staining pattern on ethanol-fixed human neutrophils. Conversely, none of 12 sera from patients with vasculitis whose sera contained anti-MPO antibodies reacted with TPO. Sera from three patients in this study contained significant levels of anti-TPO antibodies, which may have caused the positive result in the MPO ELISA. It is thus important to recognise the presence of thyroid microsomal antibodies as a possible cause of an unexpectedly positive anti-MPO or ANCA test in some patients.

We noted an unexpected association between rheumatoid lung disease and antiMPO antibodies. The association of acute pulmonary haemorrhage, lung vasculitis and presence of ANCA is well known. ANCA have also been described in idiopathic pulmonary fibrosis $^{24}$ and in these cases an occult pulmonary vasculitis was suggested. The steadily since penicillamine was started although there was no additional clinical evidence of drug induced lupus syndrome. The titre of IgM anti-MPO antibodies also rose 
presence of anti-MPO antibodies in sera from patients with RA-associated pulmonary fibrosis may imply that a sub-clinical pulmonary vasculitis may also lead to fibrosis in these patients. Further studies of anti-MPO antibodies in these and other patients with rheumatoid lung disease are being carried out in this department.

In this study we found $90 \%$ of sera from patients with vasculitis contained IgG4 antiMPO antibodies, compared with only $18 \%$ of positive sera from RA patients where antibodies of the IgG1 and 3 subclasses predominated. Of the two patients with rheumatoid arthritis who had IgG4 anti-MPO antibodies one had long standing active disease and cutaneous vasculitis. Studies of stored sera showed he had had anti-MPO antibodies in his sera for 15 years. Anti-MPO antibodies in the other patient with IgG4 anti-MPO antibodies had been present for the two years for which sera were available. Stored sera were available from four other anti-MPO antibody positive patients with rheumatoid arthritis. Anti-MPO antibodies had been present in all these sera for more than six years, but none of these antibodies was of the IgG4 subclass.

Antibodies of the IgG4 sub-class are closely associated with eosinophilia, raised levels of IgE and hypersensitivity (which is often a feature of some forms of vasculitis), ${ }^{25}$ and also linked with prolonged exposure to antigen. ${ }^{26}$ The relative paucity of IgG4 anti-MPO antibodies in patients with RA compared with vasculitis patients may reflect differences in the relative length of exposure to the antigenic stimulus and the balance between $T$ cell regulatory factors at the site of antigenic stimulus. In vasculitis, there is some evidence for a long interval between the appearance of ANCA and clinical disease. In contrast, antiMPO antibodies present in sera from the three patients with rheumatoid lung disease reported here were of $\operatorname{IgG} 1$, and 3 subclasses and antiMPO antibodies were first detected in the serum within six months of diagnosis of lung disease. The close association of systemic vasculitis with infections has suggested that the development of ANCA in this situation may result from cross reaction with infecting organisms. The likely site of infection, and of initiation of the antibody response, is the respiratory tract. In rheumatoid arthritis, the appearance of anti-MPO antibodies and antibodies to other neutrophil enzymes may be the consequence of neutrophil destruction within the rheumatoid joint, the primary site of tissue destruction, possibly due to the presence of increased lymphocyte and accessory cell traffic. The balance of $T$ cell regulatory factors at the site of antigen presentation-possibly the joint in RA and the lung in systemic vasculitis-may help to explain the difference in IgG subclasses in the two conditions.

Solid phase assays for the detection of ANCA are now widely available and increasingly used by rheumatologists to investigate patients with autoimmune rheumatic disease as well as systemic vasculitis. More information about the incidence and clinical correlates of autoantibodies reacting specifically with neutrophil granule proteins is needed to allow these assay results to be interpreted. The availability of patients in the Middlesex Hospital RA Prospective Study has enabled us to investigate in detail the circulating autoantibody response to one of these granule proteins in a well characterised group of patients with RA.

We thank Dr F Blanco for his helpful advice in the preparation of this paper.

1 Hagen E C, Ballieux B E P B, van Es L A, Daha M A R, van der Woude $F$ J. Antineutrophil cytoplasmic antibodies: A review of the antigens involved, the assays, and the possible pathogenetic consequences. Blood 1993; 81: $1996-2002$.

2 Falk R J, Becker M, Terrell R, Jennette J C. Antimyeloperoxidase autoantibodies react with native but not denatured myeloperoxidase. Clin Exp Immunol 1992; 89, 274-8

3 Roberts D E, Peebles C, Curd J G, Tan E M, Rubin R L Autoantibodies to native myeloperoxidase in patients with pulmonary haemorrhage and acute renal failure. $f \mathrm{Clin}$ Immunol 1991; 6: 389-96.

4 Lesavre P. Antineutrophil cytoplasmic autoantibodies antigen specificity. Am $\mathcal{F}$ Kidney Dis $1991 ; 18: 159-63$.

5 Gross W L, Schmitt W H, Csernok E. Antineutrophil cytoplasmic antibody-associated diseases: rheumatologist's perspective. Am f Kid Dis 1991; 18: rheum 175 .

6 Cambridge G, Rampton D S, Stevens T R J, McCarthy D A, Kamm M, Leaker B. Anti-neutrophil antibodies in inflammatory bowel disease: prevalence and diagnostic role. Gut 1992; 33: 6668-74

7 Coremans I E M, Hagen E C, Daha M R, et al. Antilactoferrin antibodies in patients with rheumatoid arthritis are associated with vasculitis. Arthritis Rheum 1992; 35: 1466-75.

8 Laussoued S, Sixou L, Oksman F, Pages M, Fournie A Antineutrophil cytoplasmic antibodies and antibodies to myeloperoxidase in rheumatoid arthritis. Arthritis Rheum 1991; 34: 1069-70.

9 Nassberger L, Sjoholm A G, Sturfelt G. Absence of circulating antineutrophil cytoplasm antibodies (ANCA) in severe vasculitis associated with rheumatoid arthritis. Scand F Rheumatol 1990; 19: 189-92.

10 Savige J A, Gallicchio M C, Stockman A, et al. Antineutrophil cytoplasm antibodies in rheumatoid arthritis. Clin Exp Immunol 1991; 86: 92-8.

11 Cohen Tervaert J W, Goldshmeding R, Elema J D, et al. Association of autoantibodies to myeloperoxidase with different forms of vasculitis. Arthritis Rheum 1990; 33 1264-72.

12 Shur P H. IgC sub-classes-a review. Ann Allergy 1987; 58 89-99.

13 Kacaki J N, Callerane M L, Blomgren S E, Vaughn J H. Immunoglobulin $\mathrm{G}$ subclasses of antinuclear antibodies and renal deposits. Arthritis Rheum 1971;14: 276-82.

14 Devey M E, Lee S R, Le Page S, Feldmen R, Isenberg D A. Serial studies of the IgG subclass and functional A. Serial studies of the IgG subclass and functional
affinity of DNA antibodies in systemic lupus affinity of DNA antibodies in systemic

15 Brouwer E, Cohen-Teveart J W, Horst G, et al. Predominance of IgG1 and IgG4 sub-class of antineutrophil cytoplasmic antibodies (ANCA) in patients with Wegener's granulomatosis and clinically related disorders. Clin Exp Immunol 1991; 83: 379-86.

16 Esnault V L M, Jayne D R W, Weetman A P Lockwood C $M$. IgG subclass distribution and relative functional affinity of antimyeloperoxidase antibodies in systemic vasculitis at presentation and during follow-up. Immunology 1991; 74: 714-18.

17 Fleming A, Crown J, Corbett $M$. Extra-articular features in early rheumatoid disease. $B M \mathcal{F} 1976$; i: $1241-5$.

18 Fleming A, Crown J, Corbett M. Prognostic value of early features in rheumatoid disease. $B M \mathcal{F} 1976$; i: 1243-7.

19 A committee of the American Rheumatism Association. Diagnostic criteria in rheumatoid arthritis: 1958 revision. Ann Rheum Dis 1959; 18: 49-53.

20 Moodie F D L, Leaker B, Cambridge G, Totty N, Segal A W. Alpha enolase: a novel cytosolic autoantigen in ANCA W. Alpha enolase: a novel cytosolic autoantigen
positive vasculitis. Kidney Int 1993; 43: $675-81$.

21 Mathieson N R, Wong P S, Travis J. Isolation and properties of human neutrophil myeloperoxidase. Biochemistry 1991; of human neu $235-330$.

22 Blanco F, Kalski J, Ravirajan C T, Speight P, Bradwell A $R$, Isenberg D A. IgG subclasses in systemic lupus erythematosus and other autoimmune rheumatic diseases. Lupus 1992; 1: 391-9. 
23 Laemmli U K. Cleavage of structural proteins during the assembly of the head of bacteriophage T4. Nature 1970 227: $680-5$.

24 Nada A K, Torres V E, Ryu J H, Lie J T, Holley K E. Pulmonary fibrosis as an unusual clinical manifestation of a pulmonary-renal vasculitis in elderly patients. Mayo Clin Proc 1990; 65: 847-56.
25 Conn D L, McDuffie F C, Holley K E, Schroeter A L. Immunologic mechanisms in systemic vasculitis. Mayo Clin Proc 1976; 51: 511-21.

26 Aalberse R C, van der Gaag R, van Leewen J. Serologic aspects of IgG4 antibodies. I. Prolonged exposure results in a IgG4-restricted response. F Immunol 1983; 130: $722-6$. 